the descending aorta allowed right-to-left shunting and prevented RV failure by relieving suprasystemic RV pressure to a systemic pressure level. The position of the distal shunt anastomosis distal to the subclavian artery would prevent a desaturation of the head vessels and upper extremity. This approach was combined with atrioseptectomy and bPAB to protect the pulmonary circulation from volume overload. Cardiopulmonary bypass was necessary for creation of the neo-ductus arteriosus for this patient in a critical hemodynamic situation. We therefore opted for a concomitant surgical atrial septectomy during the procedure. Furthermore, the result of a surgical atrioseptectomy under direct vision is in our view the most reliable route for a longer-term nonobstructive atrial septum.

At the same time that bPAB prevented active hypercirculation, atrioseptectomy avoided passive pulmonary flow obstruction. The measured pressure gradient of $55 \mathrm{~mm} \mathrm{Hg}$ across the bPAB highlights the fall in pulmonary vascular resistance. The increase in systemic blood flow, however, occurred at the expense of oxygen desaturation of the lower part of the body, as described in patients with idiopathic $\mathrm{PH}$ who were treated with a reversed Potts shunt. ${ }^{5}$
The aim of our rescue procedure was to prevent further episodes of cardiac decompensation caused by $\mathrm{PH}$ crises and leading to resuscitation. Whether the decline in the pulmonary vascular resistance would allow a successful heart transplant, or even a biventricular repair, however, remains unknown. Most probably, our strategy would allow a safer waiting time for a combined heart and lung transplant in future.

\section{References}

1. Akintürk H, Michel-Behnke I, Valeske K, Mueller M, Thul J, Bauer J, et al. Hybrid transcatheter-surgical palliation: basis for univentricular or biventricular repair: the Giessen experience. Pediatr Cardiol. 2007;28:79-87.

2. Gan CT, Lankhaar JW, Marcus JT, Westerhof N, Marques KM, Bronzwaer JG, et al. Impaired left ventricular filling due to right-to-left ventricular interaction in patients with pulmonary arterial hypertension. Am J Physiol Heart Circ Physiol. 2006;290:H1528-33.

3. Latus H, Apitz C, Schmidt D, Jux C, Mueller M, Bauer J, et al. Potts shunt and atrial septostomy in pulmonary hypertension caused by left ventricular disease. Ann Thorac Surg. 2013;96:317-9.

4. Latus H, Apitz C, Moysich A, Kerst G, Jux C, Bauer J, et al. Creation of a functional Potts shunt by stenting the persistent arterial duct in newborns and infants with suprasystemic pulmonary hypertension of various etiologies. J Heart Lung Transplant. 2014;33:542-6.

5. Blanc J, Vouhe P, Bonnet D. Potts shunt in patients with pulmonary hypertension. N Engl J Med. 2004;350:623.

\title{
Lessons learned from failed attempt at transcatheter closure of postoperative Gerbode defect
}

\author{
Syed T. Hussain, MD, ${ }^{\mathrm{a}}$ Kwabena Mawulawde, MD, ${ }^{\mathrm{a}}$ Samir R. Kapadia, MD, ${ }^{\mathrm{b}}$ \\ Eugene H. Blackstone, MD, ${ }^{\mathrm{a}, \mathrm{c}}$ and Gösta B. Pettersson, $\mathrm{MD}, \mathrm{PhD},{ }^{\mathrm{a}}$ Cleveland, Ohio
}

Video clip is available online.

The Gerbode defect, a direct communication between the left ventricle (LV) and right atrium (RA), is rare and may be either congenital or acquired. Acquired defects may be

\footnotetext{
From the Departments of Thoracic and Cardiovascular Surgery ${ }^{\mathrm{a}}$ and Cardiovascular Medicine, ${ }^{\mathrm{b}}$ Heart and Vascular Institute, and Department of Quantitative Health Sciences, ${ }^{\mathrm{c}}$ Research Institute, Cleveland Clinic, Cleveland, Ohio.

Disclosures: Authors have nothing to disclose with regard to commercial support.

Received for publication June 11, 2014; accepted for publication June 12, 2014; available ahead of print Aug 21, 2014.

Address for reprints: Gösta B. Pettersson, MD, PhD, Department of Thoracic and Cardiovascular Surgery, Cleveland Clinic, 9500 Euclid Ave, Desk J4-1, Cleveland, OH 44195 (E-mail: petterg@ ccf.org).

J Thorac Cardiovasc Surg 2014;148:e228-30

$0022-5223 / \$ 36.00$

Copyright (C) 2014 by The American Association for Thoracic Surgery

http://dx.doi.org/10.1016/j.jtcvs.2014.06.077
}

a result of complications of cardiac surgery, including aortic, mitral, or tricuspid valve repair or replacement, closure of a ventricular septal defect, endocarditis, or trauma. ${ }^{1}$ Surgical correction has been the treatment of choice, although a few case reports of transcatheter closure have recently been published. ${ }^{2}$ We report a case of surgical closure of an LV-RA shunt acquired after reoperative aortic and mitral valve surgery for remote infective endocarditis (IE), after a failed attempt to close the defect with the transcatheter approach.

\section{CLINICAL SUMMARY}

A 45-year-old man had undergone aortic valve (AV) replacement and mitral valve (MV) repair for IE in 2006. Recurrent IE in 2008 was treated with antibiotics. In 2013, he developed shortness of breath and was found to have degeneration of his AV bioprosthesis and heart failure. He underwent reoperation and had his aortic prosthesis 

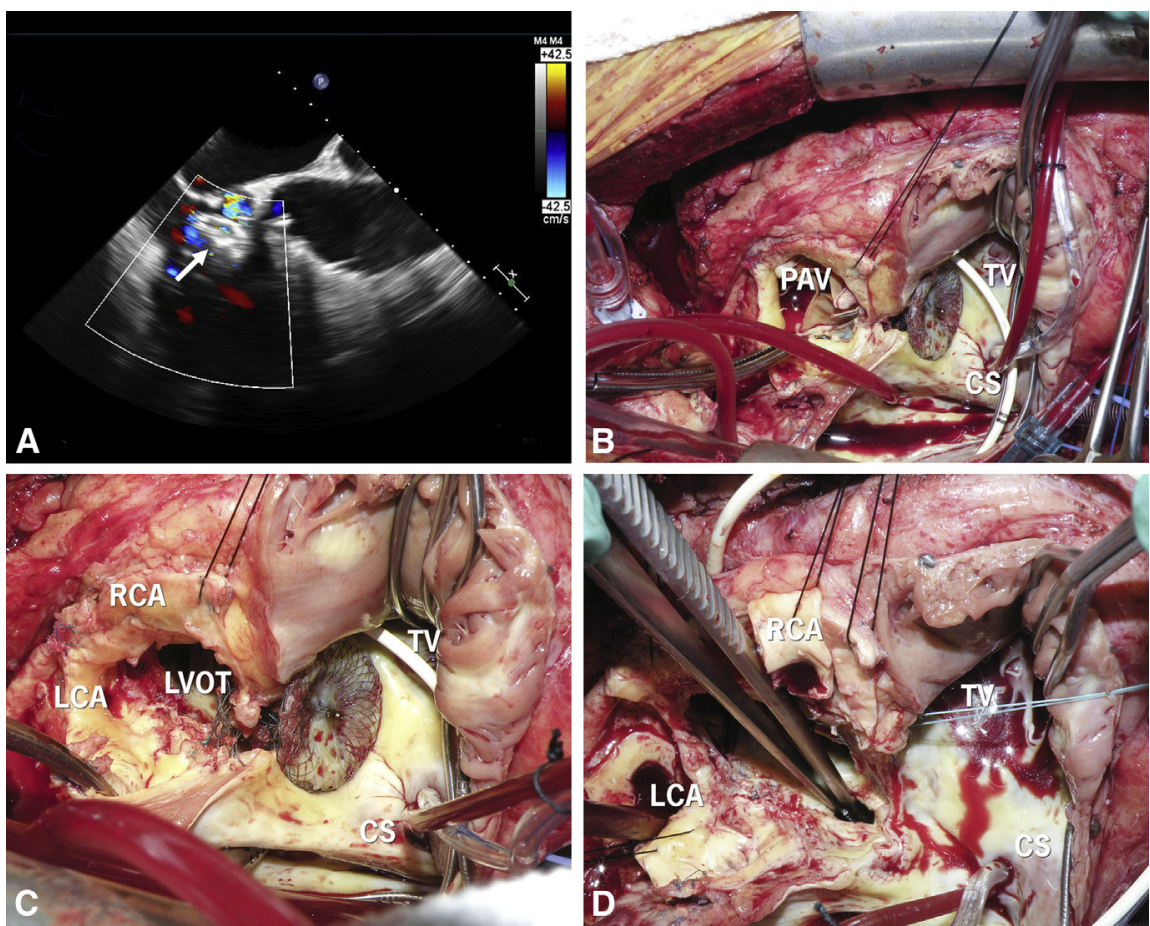

FIGURE 1. A, Preoperative echocardiogram showing the Amplatzer device (arrow) used to cover the Gerbode defect with residual left to right shunt. Amplatzer device in place before (B) and after (C) the aortic bioprosthesis removal. D, The defect in the anterior mitral leaflet (forceps). PAV, Prosthetic aortic valve; $T V$, tricuspid valve; $C S$, coronary sinus; $R C A$, right coronary artery; $L C A$, left coronary artery; $L V O T$, left ventricular outflow tract.

replaced with a no. 23 bioprosthetic valve. He developed complete heart block and required a permanent pacemaker. Within a few days he began to experience even worse shortness of breath, and echocardiography revealed a very large LV-RA fistula. Cardiac catheterization measured a $\mathrm{Q}_{\mathrm{p}} / \mathrm{Q}_{\mathrm{s}}$ ratio of 3:1. He developed progressive heart failure with fluid retention and ascites. Closure with an Amplatzer device was performed, but he continued to experience worsening heart failure symptoms, fatigue and ascites, intravascular hemolysis, and renal insufficiency. An echocardiogram revealed that he still had a large residual shunt. He became jaundiced and required repeated large-volume paracentesis. He presented to our institution in critically ill condition. An echocardiogram showed 3+ mitral regurgitation (MR), 4+ tricuspid regurgitation, and a large LV-RA shunt observed around the Amplatzer device (Figure 1, $A$, and Video 1).

He underwent a third reoperation the next day. After transecting the aorta above the sinotubular junction, the aorta and RA wall were opened down to the Amplatzer device. There was a huge hole between the RA and LV below the bioprosthetic AV, with the Amplatzer device sitting in it (Figure 1, $B$ and $C$ ). There was also an anterior mitral leaflet perforation (Figure 1, D). The aortic bioprosthesis and Amplatzer device were removed and the anulus debrided. The MV perforation was closed and the tricuspid valve repaired with an annuloplasty ring. The aortic root was reconstructed with a no. 24 aortic allograft. The patient's postoperative course was uneventful, and follow-up echocardiogram demonstrated a well-seated allograft without regurgitation, competent mitral and tricuspid valves, and no residual LV-RA shunt.

\section{DISCUSSION}

Acquired LV-RA communication (a Gerbode defect) is rare and arises mostly from complications of endocarditis and cardiac surgery. Most defects are small and caused by aortic or tricuspid valve sutures. Reoperations have also been reported as a risk factor. ${ }^{1}$ If significant, surgical correction has been the treatment of choice, although the procedure carries high risk. ${ }^{1}$ The surgical approach is best accomplished with a combined aortic/atrial approach, which allows for visualization of both ends of the fistula and the subsequent repair.

Increasing experience with transcatheter devices has resulted in nearly one-third of acquired LV-RA shunts in Europe being closed percutaneously during the last decade. ${ }^{1,2}$ Devices have also been reported to cause erosion of the aortic or atrial wall, resulting in fistulas. ${ }^{3,4}$ The perforation in the base of the anterior mitral leaflet was in a position that suggested erosion as a possible cause. Our patient's LV-RA defect was below the aortic prosthesis, suggesting dehiscence of AV sutures placed at the entry of a pseudoaneurysm rupturing postoperatively into the RA. 
When recognized postoperatively, the patient's past history of IE, 2 cardiac operations, and poor clinical condition suggested that another reoperation would be high risk, which led to the decision to close the fistula with an Amplatzer device. Failure to close the shunt percutaneously worsened his heart failure and resulted in ascites, intravascular hemolysis, jaundice, and renal failure. Successful cases of transcatheter closure of acquired LV-RA fistulas have been reported, ${ }^{2}$ and device closure was a reasonable option in this patient, although longterm results are unknown. In our case, however, when the device closure had failed and the patient's heart failure worsened, there was little excuse for not referring this young man early to a center with more experience performing complex reoperations.
In conclusion, transcatheter device closure of acquired LV-RA fistulas can be justified and attempted, but if unsuccessful, surgery should be reconsidered early, before the patient becomes inoperable with multiorgan failure.

\section{References}

1. Sinisalo JP, Sreeram N, Jokinen E, Qureshi SA. Acquired left ventricular-right atrium shunts. Eur J Cardiothorac Surg. 2011;39:500-6.

2. Sinisalo JP, Sreeram N, Qureshi SA. Transcatheter closure of acquired left ventricle to right atrium shunts. Catheter Cardiovasc Interv. 2013;82: E809-14.

3. Crawford GB, Brindis RG, Krucoff MW, Mansalis BP, Carroll JD. Percutaneous atrial septal occluder devices and cardiac erosion: a review of literature. Catheter Cardiovasc Interv. 2012;80:157-67.

4. Mello DM, Fahey J, Kopf GS. Repair of aortic-left atrial fistula following the transcatheter closure of an atrial septal defect. Ann Thorac Surg. 2005;80: 1495-8.

\title{
Sternal metastasis of renal cell carcinoma: The role of metastasectomy
}

\author{
Naruhiko Ikoma, MD, and Ara Vaporciyan, MD, Houston, Tex
}

Sternal metastasis of renal cell carcinoma (RCC) has rarely been reported in the literature. ${ }^{1}$ This case series describes the presentation and management of 3 patients with isolated sternal metastasis of RCC treated with sternectomy with curative intent.

\section{CLINICAL SUMMARIES Patient 1}

A 40-year-old man was seen in April 2004 with an enlarging sternal mass. Computed tomography revealed a lytic lesion involving the entire manubrium and a mass in the left kidney. Biopsy of the renal mass revealed an unclassified RCC. Despite chemotherapy, the disease progressed. In October 2004, the patient underwent en bloc chest wall resection of a portion of the sternum, both clavicular heads, and the medial first and second ribs. Reconstruction was performed with Prolene mesh (Ethicon, Inc, Somerville, $\mathrm{NJ})$ and a left pectoralis major muscle flap. The pathology report indicated an $8.5 \times 6.5 \times 6.0-\mathrm{cm}$ metastatic RCC.

From the Thoracic Surgery Department, MD Anderson Cancer Center, Houston, Tex. Disclosures: Authors have nothing to disclose with regard to commercial support.

Received for publication Dec 23, 2013; revisions received April 17, 2014; accepted for publication June 10, 2014; available ahead of print Aug 21, 2014.

Address for reprints: Ara Vaporciyan, MD, Room 19.6008, 1400 Pressler, Houston, TX 77030 (E-mail: avaporci@mdanderson.org).

J Thorac Cardiovasc Surg 2014;148:e230-1

0022-5223/\$0.00

Published by Elsevier Inc. on behalf of The American Association for Thoracic Surgery

http://dx.doi.org/10.1016/j.jtcvs.2014.06.081
In December 2004, left radical nephrectomy was performed, and the pathology report revealed a $6.5-\mathrm{cm}$ unclassified RCC (Fuhrman nuclear grade 3) with invasion into the perinephric adipose tissue and vascular lymphatic spaces. In July 2007, brain and rib metastases were discovered. The patient underwent stereotactic radiosurgery and several craniotomies, followed by chemotherapy; however, the disease progressed, and the patient died in April 2011.

\section{Patient 2}

A 60-year-old man was seen with an enlarging sternal mass in February 2013. Biopsy revealed metastatic RCC, and computed tomography revealed a right kidney tumor. A right radical nephrectomy was performed in May 2013. The histopathologic diagnosis was clear cell RCC (Fuhrman nuclear grade 3). Because of the large size of the sternal metastasis, the patient underwent adjuvant chemotherapy, to which there was partial response. In October 2013, the patient underwent total sternectomy and reconstruction with GORE-TEX mesh (W. L. Gore \& Associates, Flagstaff, Ariz), titanium sternal bars, bilateral pectoralis major flaps, and pedicled right rectus abdominis muscle flap. The pathology report of the sternal lesion revealed an $8.5 \times 7.3-\mathrm{cm}$ metastatic RCC.

\section{Patient 3}

A 47-year-old man was seen with a painful mass at the medial border of his left clavicle. Biopsy in November 